\title{
La disputa del pasado: "desmasculinización" del espacio minero. Los efectos de la reconversión laboral y productiva en Lota y Coronel*.
}

Cristina Andrea Moyano Barahona* Ana Francisca Viveros ${ }^{* * *}$

Resumen: La crisis terminal de la industria carbonífera en Chile generó una crisis social significativa en la cuenca de Arauco. Las políticas de reconversión laboral y productiva implementadas por los dos primeros gobiernos de la Concertación fueron un fracaso. Sin embargo, dichas políticas tuvieron un efecto no buscado. Mientras los ex mineros se convertían en cesantes crónicos, las mujeres aprovecharon las pocas ofertas laborales disponibles y salieron del mundo doméstico para convertirse en jefas de hogar.

En este trabajo abordaremos cómo impactó ese proceso de incorporación de mujeres al mundo laboral, en la disputa por la resignificación del pasado de la sociedad minera. En suma, cómo las mujeres pusieron en entredicho la construcción masculina de la vieja sociedad minera y avanzaron en un proceso de desmasculinización del mundo pasado para resituarse en el presente que estaban viviendo. Palabras clave: Mundo del carbón. Memoria. Transformaciones culturales.

\footnotetext{
* Articulo elaborado en el marco del proyecto de inserción posdoctoral $\mathrm{N}^{\circ}$ 79090004. Citado por Vivallos y Brito. Op. Cit. p. 36-37 Fundación Instituto de Estudios Laborales, "Estudio Cuantitativo y Cualitativo sobre la Realidad Laboral en las Comunas de la Cuenca del Carbón”, 2009;

* Doctora en Historia - Académica Universidad de Santiago de Chile; E-mail: cristina.moyano@usach.cl

*** Magister en Cultura y Pensamiento Europeo. Académica Universidad de Santiago de Chile. E-mail: anafranciscavg@gmail.com
} 
La disputa del pasado: "desmasculinización" del espacio minero...

\section{Introducción}

La crisis de la actividad carbonífera en Chile, comenzó a hacerse evidente en la década de 1960. Altos costos productivos, competencia con mercados externos y agotamiento visible del proyecto ISI, pusieron en jaque una industria que había sustentado el crecimiento y desarrollo no sólo de una actividad económica, sino que también a un conjunto de pueblos que crecieron a su alero, unas formas de asociatividad y de generación de identidad. En suma, una formación social en su conjunto.

Esta crisis de larga duración vino a volverse aguda hacia la década de 1990. El cierre de la minera privada Schwager en 1993, seguido por el cierre de las minas de Lota que estaban en manos de la empresa estatal Enacar, volvieron a visibilizar en el espacio público esa sociedad que se había formado en torno al carbón y que agonizaba terminalmente como uno de los efectos de la aplicación de un nuevo modelo de desarrollo, implementado desde fines de la década de los 70 , con orientación primario exportador de corte neoliberal y que había puesto fin al agotado modelo ISI. Cuando los mineros salieron a las calles para pedir ayuda al Estado, salieron con ellos indicadores de una sociedad postrada en un subdesarrollo agudo, con altos índices de pobreza, desempleo y marginalidad.

El gobierno chileno, liderado por la Concertación de Partidos por la Democracia, tuvo que tomar en sus manos resolver la enorme crisis social que se suscitaba por el cierre definitivo de las minas de carbón. El costo social era enorme, pero el predominio de una visión económica neoliberal que sustentaba la necesidad de cerrar todas aquellas empresas estatales que generaban perdidas y tenían baja productividad, primó en los análisis de la época y contó además con un apoyo transversal en el empresariado y la derecha política.

Para tratar de enfrentar los costos sociales de dicho proceso, la Concertación implementó un proyecto de Reconversión Productiva y Laboral (Ley 19.129 y 19.173 de 1992) que tenía como objetivo dotar de nuevos conocimientos y habilidades a los trabajadores que quedarían cesantes y posibilitar con ello la reinserción laboral en actividades productivas nuevas que deberían instalarse en la zona.

Anos 90, Porto Alegre, v. 19, n. 36, p. 283-314, dez. 2012 
La reconversión laboral y productiva fue un fracaso. Sin embargo, tuvo un efecto no buscado. Mientras los ex mineros se convertían en cesantes crónicos, las mujeres aprovecharon las pocas ofertas laborales disponibles y salieron del mundo doméstico para convertirse en jefas de hogar.

En este trabajo abordaremos cómo impactó ese proceso de incorporación de mujeres al mundo laboral, en la disputa por la resignificación del pasado de la sociedad minera. En suma, cómo las mujeres pusieron en entredicho la construcción masculina de la vieja sociedad minera y comenzaron un proceso de desmasculinización del mundo pasado para resituarse en el presente que estaban viviendo.

\section{La memoria y los usos del pasado. Algunas reflexiones teóricas}

El pasado no se encuentra cerrado, sino que abierto y en permanente disputa. No sólo el más reciente es objeto de luchas por la resignificación, sino que también aquellos más lejanos, aquellos que son fuente de identidad colectiva y que han impreso en distintos actores sellos característicos que los sitúan desde el presente para construir un futuro próximo y lejano.

Tal como planteara Ricoeur, la memoria es productiva, es un trabajo que conlleva voluntariedad, esfuerzo, imaginación y por ende, no es algo espontáneo ni instantáneo. Desde la escuela más subjetivista hasta aquella que pone mayor énfasis en los componentes sociales del recuerdo, existe el consenso respecto de que el acto de recordar contiene una aporía intrínseca: el recuerdo de la cosa ausente, la presencia de lo que ya no está, de lo que ha desaparecido y de lo que sólo queda el rastro de la narración que lo presencializa.

$\mathrm{El}$ acto de narrar contiene por tanto los componentes claves de memoria e instalan su segunda aporía. Creemos ser fiel a la imagen de la cosa ausente, sin embargo, en la representación narrativa, la necesidad de transmitir sentidos y sensaciones implica un proceso de transformación, de construcción lógica cronotópica (ARFURCH, 2005), que vincula a la memoria con los componentes ficcionales de cualquier relato. En suma la fidelidad a la imagen

Anos 90, Porto Alegre, v. 19, n. 36, p. 283-314, dez. 2012 
La disputa del pasado: "desmasculinización" del espacio minero...

de la cosa ausente sólo se sustenta en un acto de fe, de creer que el relato de lo ocurrido no afectó la experiencia vivida, ahora narrada para ser transmitida. Sin embargo, la sola presencialidad extemporánea contiene la anomalía de la transmisión y la pérdida de empiria. En pos de la significación, se ordena, se selecciona y se olvida.

Estas aporías intrínsecas a la memoria y al acto de recordar nos permiten comprender que detrás de este acto subjetivo, aparentemente individual, es casi imposible disectar lo propiamente intimo de aquello social en el que recordamos, en el que damos sentido y significado a las experiencias y, en el que por cierto, basamos también la intersubjetividad de la confianza y fidelidad del relato construido.

Esa intersubjetividad social está estructurada en un conjunto de posicionalidades que construyen los soportes desde los cuales se narra. En primer lugar, el tiempo, como construcción temporal que permite la dotación de sentido, que articula el antes y el después del relato y que va ordenando como cadena lógica un conjunto de hitos cuya concatenación se va conectando con otros relatos con los que establece correspondencia y gana en credibilidad.

En segundo lugar, el espacio, entendido como campo en el que se sitúa la experiencia intersubjetiva es dinámico. El espacio, el hogar, la ciudad, el lugar de trabajo, lo íntimo, van articulando una red de lugares desde los cuales se anclan los hechos de la experiencia narrada y que permiten estructurar un sentido compartido, un significado contextual. Por otro lado también, el espacio es contenedor de experiencias colectivas, de redes sociales, de vinculación con otros, que permiten establecer los posibles testigos, vicarios de la validez del relato a posterior.

El espacio minero carbonífero de la provincia de Arauco, se constituye en un espacio de experiencia intersubjetiva. Ordenado de acuerdo a los intereses económicos de la explotación de carbón, fue construyéndose un espacio de habitabilidad propio de la zona y que será fuente de identidad y soporte de recuerdos sobre los cuales se estructurará el relato de los actores sociales. La mina y su interior, un espacio eminentemente masculino (FIGUEROA, 2009), caracterizado por la oscuridad, la peligrosidad, la dureza y las experiencias de solidaridad entre los distintos fragmentos de la división del trabajo, es un primer espacio de narración, en el subsuelo, desde el cual los mineros hombres van construyendo su identidad social e individual.

Anos 90, Porto Alegre, v. 19, n. 36, p. 283-314, dez. 2012 
En el exterior todo un espacio abierto. El espacio de los técnicos y administrativos, de los que circulan alrededor de las minas, pirquineros y perreros, recolectores de restos de carbón. Una ciudad ordenada en torno a la división de trabajo, con espacios diferenciados en los que se plasma la desigualdad y las jerarquías.

En el espacio exterior también se sitúa el mundo femenino. La mujer del minero, que va construyendo un espacio doméstico que excede las murallas del hogar y los pabellones colectivos (FIGUEROA, 2009). En el horno para hacer el pan, en la construcción de redes de sociabilidad hay un mundo minero femenino bastante invisibilizado y que durante muchos años tuvo conflictos para narrarse, para situarse en el espacio, para dotar de sentido a la identidad femenina.

Por ello un tercer componente de la narrativa está vinculado al género. La construcción sociopolítica y cultural de lo "femenino" y lo "masculino" estructuran también soportes representacionales desde los cuales se constituye la experiencia y por ende, desde donde también se articulan los relatos de memoria.

La construcción del concepto de género introduce en el campo de estudio de lo social la consideración de que lo femenino y lo masculino son una representación cultural realizada en base a la simbolización de la diferencia sexual, proceso situado contextualmente a lo largo del devenir histórico (SCOTT, 1985; 1990). Como plantea Marcela Morales Ll., "en el ámbito académico, su incorporación a partir de la década de los noventa, también ha contribuido a tensionar modelos esquemáticos y macro-estructurales de comprensión de la vida social, revalorando las subjetividades, las construcciones de discursos y de la vida cotidiana. Junto con el denominado giro subjetivo (SARLO, 2005), esta perspectiva ha aportado a la transformación de las narrativas socio-históricas y a la revalorización del papel de las personas antes anónimas - particularmente mujeres y otros grupos subalternizados - en los devenires históricos" (MORALES, 2011).

Según Scott el género constituye una forma primaria de las relaciones significantes del poder, esto porque hombres y mujeres acceden de manera diferenciada a los distintos recursos sociales, políticos, materiales y económicos, estructurando marcos de experiencia desde el cual articulan su propia construcción de la realidad social. "En tanto categoría analítica, Scott propone el análisis de género en

Anos 90, Porto Alegre, v. 19, n. 36, p. 283-314, dez. 2012 
cuatro dimensiones: los símbolos y los mitos culturalmente disponibles que evocan representaciones, los conceptos normativos que manifiestan las interpretaciones de los significados de los símbolos (doctrinas religiosas, educativas, científicas, legales y políticas que afirman categórica y unívocamente el significado de varón y mujer masculino y femenino), las instituciones y las organizaciones sociales de las relaciones de género (sistema de parentesco, la familia, el mercado de trabajo segregado por sexos, las instituciones educativas, la política) y las identidades de género" (MORALES, 2011).

El género por tanto es clave en la comprensión no sólo de las experiencias sociales diferenciadas en la cotidianeidad, sino que también en la disputa por el pasado vivido. Las representaciones, los imaginarios sociales, los accesos diferenciados a los recursos simbólicos, culturales y económicos, están en la clave de la construcción de las identidades sociales en permanente proceso de resignificación, de allí que sean también clave en la forma de narrar el pasado vivido, así como la transmisión del mismo.

Tal como esbozamos anteriormente, la sociedad minera del carbón se simboliza desde lo masculino. Es la imagen del minero, hombre, joven, productor y proveedor, la representación predominante que vincula pasado con presente. Sin embargo, el proceso de crisis terminal y cierre de las minas en la zona de Arauco, pondrá en tensión ese pasado y también el presente.

La cesantía azotó el espacio minero y dejó a los hombres sin la capacidad de representarse como proveedores. La reconversión no logró insertar en las nuevas dinámicas económicas a todos los hombres que quedaron sin trabajo, la mayoría de ellos con muchos años de minero en su experiencia y resistiéndose a la incorporación a otras actividades. En ese contexto, la reconversión generó un efecto sociocultural significativo. Mujeres y jóvenes se adaptaron de mejor forma a las escasas ofertas laborales y esa nueva experiencia laboral, permitió ir disputando la imagen y representación de la sociedad minera, junto con reordenar de otra forma las relaciones de poder al interior del espacio carbonífero. 


\section{Cambios estructurales y cambios en la identidad. Las trayectorias laborales de los ex mineros}

La actividad carbonífera se constituyó como tal hacia la primera mitad del siglo XIX, tomando importancia para el desarrollo nacional hacia la segunda mitad del siglo y hasta la década de 1940. Desde allí en adelante, la actividad extractiva del carbón vivió un conjunto de fluctuaciones asociadas tanto a los cambios en los modelo de desarrollo nacional, como al aumento de los costos de la extracción y la falta de competitividad ante el mercado internacional.

Pese a lo anterior, la importancia de la extracción del carbón generó en la zona una potente relación entre trabajo e identidad. Así como lo indican Vivallos y Brito, "[...] el proceso de construcción de un sentido de identidad de los mineros del carbón de Lota, se ha desarrollado de una forma particular. Esta particularidad estaría dada por la construcción de una identidad que podríamos llamar fuerte, en el entendido de ser capaz de proyectarse a toda una comunidad. Esposas, hijos u otras personas que no necesariamente realizaron la labor de mineros, pero que comparten una identidad común, la cultura del carbón. Que además es capaz de mantenerse en el tiempo, una vez que se abandona la práctica laboral que le da sentido a esa identidad, y oponerse a las diversas manifestaciones de la exclusión social"'(VIVALLOS; BRITO, 2011, p 34).

Sin embargo, si bien la identidad ha tendido a mantenerse como fuerza de contención, es cierto que la posibilidad de dotar de sentido hacia el futuro a una ciudad deprimida económicamente, con incapacidad de movilizar recursos hacia el futuro, también pesa sobre esa memoria congelada de un pasado carbonífero emblemático que dejó de existir (MOYANO, 2011).

La estocada final a la comunidad minera vino de la mano del cierre de las minas. La zona del carbón muestra los mayores índices de pobreza del conjunto nacional, así como importantes indicadores de cesantía y marginalidad. La reconversión socio laboral no logró revertir un proceso de cierre y expulsión de mano de obra que venía dándose de manera paulatina desde los años 70. "Olate (1995), en tanto, además de demostrar el escaso éxito de los planes de reconversión laboral aplicados en Lota, profundizó en los elementos

Anos 90, Porto Alegre, v. 19, n. 36, p. 283-314, dez. 2012 
La disputa del pasado: "desmasculinización" del espacio minero...

constitutivos del imaginario sociocultural de la zona, el cual estaba dado por la empresa como núcleo central y por el sindicato como elemento antagónico reforzador de aquél. Dejando en tercer lugar, con mucho menos fuerza a la Iglesia Católica. En esta relación simbólica que domina el imaginario colectivo de los habitantes de Lota, emerge principalmente el quiebre entre el sentido comunitario (solidario) y el individual, producto de la imposición del modelo económico neoliberal como una experiencia dolorosa. La reconversión laboral atentó contra los elementos constitutivos de este imaginario (empresa/sindicato) ya resquebrajado, dejando en la incertidumbre a toda una comunidad"(VIVALLOS; BRITO, 2011, p. 35).

Los años dictatoriales y la implantación forzosa del neoliberalismo generaron a nivel nacional numerosas consecuencias negativas en aquellas actividades extractivas y de producción manufacturera que habían crecido al alero de la acción del Estado. La lógica de la eficiencia y la competitividad, sumada a la idea de que el Estado debe retrotraerse a actividades subsidiarias, fueron dos componentes claves en la forma en la que se miró la minería del carbón. Durante gran parte de la dictadura militar la actividad carbonífera dio cifras rojas. Esto llevó a la privatización de ENACAR, que posteriormente volvió a manos del Estado y siguió demostrando que los altos costos productivos de la actividad hacían inviable la mantención de la empresa. Durante los años 90, en pleno periodo posdictatorial, al gobierno le resultaba muy incómodo justificar las numerosas pérdidas, déficit y subsidios con los que debía mantener esta empresa. Emblemática es la postura del periódico El Mercurio quien enfatizaba en varias de sus columnas editoriales que el costo de una administración ineficiente era pagado por todos los chilenos (MOYANO, 2011b) y que era más sano cerrar las minas y dar por terminada una actividad que no era capaz de ajustarse a las dinámicas del desarrollo nacional.

Otro de los efectos significativos que generó la implementación de las políticas neoliberales fue la disminución significativa de la clase obrera. "En 1971 existían en nuestro país 1.018.500 obreros; en 1980, 887.500 y en 1982 esa cifra sólo alcanzó a 696.600 (CORREA, 1984, p. 1). Una segunda etapa, es la vivida en el momento de la crisis de los años ochenta. Mientras que entre 1970 y 1980 los obreros se reducen en un 31,6\%, en dos años (1981-1982)

Anos 90, Porto Alegre, v. 19, n. 36, p. 283-314, dez. 2012 
disminuyeron un $21,5 \%$, junto con una caída general de todo el sector obrero formal. En este período de crisis la tendencia fue hacia el aumento espectacular del sector informal, la reducción de la capacidad productiva, la mantención del desplazamiento de la actividad económica organizada hacia el sector terciario y la acentuación de la burocratización del Estado. Estos fenómenos demostrarían, según Correa, una tendencia hacia la regresión generalizada de nuestra sociedad. En este contexto, el aumento del sector terciario constituye más un refugio para empleadores y asalariados excluidos del sector productivo, que una respuesta a demandas nuevas producidas por fenómenos modernizadores (CORREA, 1984, p. 27-30). Las conclusiones a las que llegaba Correa en 1984 eran lapidarias y pensaba la crisis como el comienzo de un camino mayor hacia el subdesarrollo del país en su conjunto. La crisis económica propició un dramático proceso de dispersión social, respecto del cual la destrucción de la mayoría de la clase obrera constituye el fenómeno central" (VIVALLOS; BRITO, 2011. p. 36).

Junto a lo anterior, es importante señalar además que hacia 1996, junto a la declinación de las ramas industriales y el crecimiento del sector terciario, se produce un proceso de desconcentración significativa de los trabajadores en los lugares donde se desempeñan. Hacia 1996, un año antes del cierre definitivo de las minas de carbón en Lota y Coronel, el 25\% de la fuerza de trabajo se desempeñaba en unidades con menos de diez operarios. "En los sectores exitosos se tendió a reemplazar a los trabajadores por tecnología de punta. Una nueva concepción del trabajo incluía al salario como un incentivo individual estrictamente sujeto a la productividad, y ya no como un derecho adquirido o como una retribución fundamental para la satisfacción de las necesidades básicas. La flexibilidad laboral fue uno de los soportes estratégicos del nuevo modelo y, en el mismo sentido, las protecciones sociales y previsionales se consideraron costos adicionales que entorpecían la competitividad y la creación de nuevos empleos. El Estado, en esta nueva concepción, tendría una labor subsidiaria, permitiendo que empresarios y trabajadores negociaran sus relaciones libremente a través del mercado (SALAZAR; PINTO, 2002, p. 184-185)"'2.

La reducción del número de trabajadores fue diezmando la organización sindical y la fuerza de los mismos para incidir en las

Anos 90, Porto Alegre, v. 19, n. 36, p. 283-314, dez. 2012 
La disputa del pasado: "desmasculinización" del espacio minero...

mejoras salariales de los propios afiliados. Hacia fines de la década de 1990 menos del 20\% de los trabajadores chilenos se encontraban afiliados a sindicatos y en un número significativo la mayoría de ellos se encontraban en receso sindical (MOYANO, 2011b).

En este nuevo escenario profundamente modificado, el cierre de las minas de carbón asestó un golpe mortal a la cultura obrera carbonífera, caracterizada por la sindicalización y la organización colectiva. En el marco de esta crisis, los sindicatos intentaron negociar con el Estado, pero fueron agentes con escaso poder de negociación política y con poco poder para incidir de manera directa en los planes que estructuraron las políticas de la reconversión laboral y productiva. Por otro lado, la representación que de ellos hizo la prensa de derecha fue nociva para su propia presentación en sociedad. Mientras se reducía el peso de los trabajadores, se fue formando una opinión pública que mostraba a los mineros del carbón como un sector privilegiado, que se mantenía a un alto costo para todos los chilenos y que escondía detrás las oscuras intenciones de sectores de la izquierda ideológica (MOYANO, 2011b) .

En este escenario fue muy complejo pensar en la readaptación de los viejos mineros, cuyas trayectorias laborales fueron bastante rígidas y enmarcadas casi en su totalidad en torno a la actividad del carbón. Según el estudio de Vivallos la mayoría de los trabajadores del carbón desarrollaron escasos trabajos antes de dedicarse a la actividad minera, que no estuvieran directa o indirectamente relacionados con la extracción del mineral. En dicha actividad fueron cambiando de labores, bajo una dinámica de ascenso hacia trabajos mejor remunerados, pero también más intensos y más peligrosos, fomentando una dinámica de representación asociada a la fortaleza física y a la valentía masculina.

Otra de las características de las trayectorias laborales de los ex mineros del carbón, se vincula a la permanencia familiar de la actividad, es decir, la mayoría de los trabajadores que se dedicaron a la minería tenían una tradición de padres y abuelos que también habían laborado en la mina. Esto fue fomentando la extensión hacia la familia de la cultura y la identidad carbonífera. Se suma a lo anterior, lo temprano del trabajo en términos etáreos. A la mina se entraba muy joven y eso generaba una larga trayectoria dedicado a un mismo trabajo y al fortalecimiento de habilidades que volvían

Anos 90, Porto Alegre, v. 19, n. 36, p. 283-314, dez. 2012 
más compleja cualquier dinámica de flexibilidad y posibilidad de reinserción laboral. Mientras más tiempo habían pasado en a mina, menos capacidad adaptativa a nuevas laborales.

Según Vivallos la gran diferencia en las trayectorias laborales de los ex mineros, radicaba en los espacios de trabajo donde se realizaban las laborales. "Lo común era trabajar al interior de las minas, en donde se necesitaba una gran cantidad de mano de obra para la explotación del carbón. Sólo dos de los mineros entrevistados desarrolló la mayor parte de su vida laboral fuera de ellas, en superficie. La situación de estos trabajadores de superficie aún hoy, cuando escribimos estas líneas, no nos deja de sorprender, ya que fueron entrevistados por su identificación con el trabajo en las minas y por su definición como mineros. Pero los mineros del interior de las minas señalaban que ellos (los otros) no eran verdaderos mineros, que nunca habían estado en el frente, con las pésimas condiciones de trabajo que ello implicaba. Estar en el frente extrayendo el carbón de la veta misma era el oficio del minero por excelencia, necesitando una combinación entre fuerza física y habilidad por sobre el promedio, "[...] usted para levantar un palo de madera, una viga, el poste del palo, ...usted tenía que tener fuerza bruta"(VIVALLOS; BRITO, 2011. p 40).

En suma las trayectorias laborales de los ex mineros del carbón, poco flexibles y dinámicas, centraron la construcción de identidad en la propia mina. De allí la importancia de dicha actividad como fuente de identidad y como soporte clave en la construcción de una cultura del carbón.

\section{La reconversión productiva y los indicadores de una crisis}

En 1992 se aplicaba el primer plan de reconversión en la zona de Lota. El eje articulador del programa postulaba la transformación del eje productivo de la zona hacia otras actividades, lo que suponía también una reconversión de la mano de obra que durante décadas y generaciones sólo sabía trabajar en una cosa: las minas de carbón ${ }^{3}$. Se retiraron 2572 trabajadores de Enacar - de 
los cuales 1783 correspondían a los establecimientos de Lota -, y 790 se acogieron a retiro voluntario con la Ley 19.129 del 02 de febrero de 1992 (CARRILLO; LETELIER, 2002). Se ofrecieron además becas y subsidios, sin embargo, el plan no tuvo los resultados esperados. En 1996 se retiran del establecimiento de Lota 426 mineros(CARRILLO; LETELIER, 2002). Pese a los incentivos, la crisis económica y productiva en Lota se agudizó y el cierre de la mina se hizo inevitable en 1997. Los trabajadores egresados de este proceso de cierre salen vinculados al convenio "Plan solidario con las familias de Lota”, que incluyó indemnizaciones, capacitación laboral, puentes de jubilación, reinserción laboral, cobertura de salud y previsión, becas de estudio, subsidio de viviendas, entre otros. Se implementó además el Plan "Lota: Desarrollo Acelerado", programa gubernamental orientado a impulsar de manera especial el desarrollo de nuevas y crecientes actividades productivas en el Golfo de Arauco y particularmente en Lota. La gestión de dicho Plan fue asumida por CORFO, mediante la creación de un Comité de Reconversión compuesto por representantes de CORFO, la Secretaria Regional Ministerial de Planificación de la VIII Región y un Coordinador Ejecutivo.

En el 2004, los informes oficiales apuntaban a que la comuna contaba con el mayor número de beneficiarios de los programas de empleo de la VIII Región: 3.600 trabajadores, auspiciados por la Corporación Nacional Forestal, el Programa de Empleo con Apoyo Fiscal, el Programa de Mejoramiento Urbano (PMU) y el Ministerio del Trabajo; en contraste con el 15,2\% de desempleo. A la alta cesantía se sumaba la baja inversión (JEREZ, 2004), lo que da cuenta de la gran cantidad de ex mineros contratados como mano de obra en programas laborales de emergencia. 


\section{Grafico 2: Evolución tasa de desocupación Provincia de Concepción}

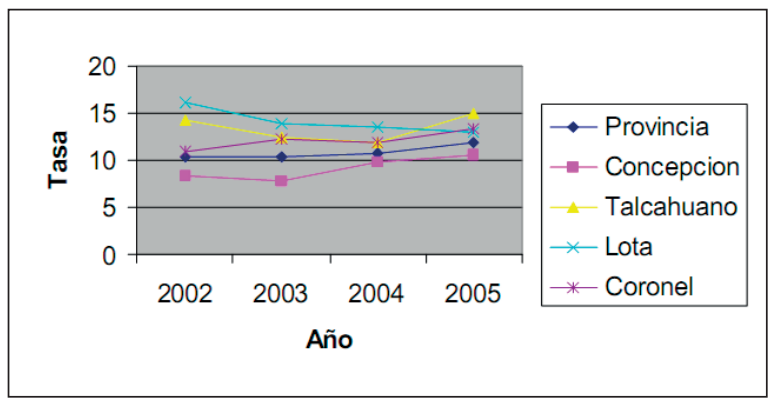

Fuente: Pino, Osvaldo y Campos, Guillermo

"Taller de Empleo regional no 16"; p. 10

Los altos índices sostenidos de desempleo en la provincia, sólo superados por Talcahuano en el 2005, demuestran la crisis estructural que generó en la ciudad el cierre definitivo de las minas de carbón y falta crónica de inversiones, generando una población y un espacio que estarán marcados por la marginalidad, la pobreza y las escasas oportunidades de integración al modelo económico y social imperante.

Así, pese a que la reconversión laboral se implementó y realizó importantes aportes, la crisis social y económica fue inminente y fue profundizándose en el tiempo. La visibilización de nuevos actores, como las mujeres o los desempleados, fue un factor de cambio en la dinámica social. Un número cada vez más importante de lotinos dejaron de trabajar en su ciudad y a la cesantía se agregó la falta de una pertinente capacitación laboral, que los dejó sin posibilidades de reinsertarse en otras actividades. Si consideramos la población total de Lota que alcanza a 49.089 habitantes para el 2002, de los cuales, 23.944 son hombres y 25.145 son mujeres ${ }^{5}$, se comprende el impacto que generó el retiro de 4831 trabajadores de la mina del carbón, entre 1992 y 1997. 
La disputa del pasado: "desmasculinización" del espacio minero...

Personal retirado de Enacar S.A

\begin{tabular}{|c|c|c|c|}
\hline Año & Lota & Carvile & Total \\
\hline 92 & 2716 & 436 & 3152 \\
\hline 93 & 77 & 12 & 89 \\
\hline 94 & 116 & 34 & 150 \\
\hline 95 & 94 & 72 & 166 \\
\hline 96 & 455 & 16 & 471 \\
\hline 97 & 1373 & 40 & 1413 \\
\hline Totales & 4831 & 610 & 5441 \\
\hline
\end{tabular}

Fuente: Elaboración propia.

Estos datos, evidencian no solo la crisis económica generada por el cierre de la mina, sino que también, el mínimo alcance que tuvo la reconversión en la economía lotina, considerando incluso la generación de 1500 empleos permanentes y de 2000 empleos transitorios. Es decir, el proceso de reconversión productiva sólo cubrió un $27,5 \%$ de la población retirada, en términos de reemplazo permanente y sumados a los transitorios (lapsus corto de tiempo) a un total de $64.3 \%$ de la mano de obra retirada de la actividad del carbón (CARRILLO; LETELIER, 2002). A ello se agrega que, de las promesas realizadas durante el gobierno de Eduardo Frei Ruiz-Tagle y que formaron parte del paquete de reconversión productiva y laboral, solo se cumplió con una parte del parque industrial, el Centro de Formación Técnica y la instalación de una oficina del Banco Estado.

Diez años después del cierre de la mina, el alcalde de ese entonces, Patricio Marchant, no dudó en afirmar que el plan de reconversión fracasó "porque no le preguntaron a las bases. Se decidió todo en Santiago y con las autoridades de la zona y lo que primó fueron promesas incumplidas, como la ruta costera, el parque industrial completo y el mejoramiento del hospital de la comuna". En ese sentido, "[...] la ciudadanía lotina no participó ni en el diagnostico, ni en el diseño, ni la evaluación, de las políticas públicas. La gente de Lota, percibió las políticas públicas como una imposición desde el Estado hacia las bases, imposición que no recoge la visión de la ciudadanía y que, por ende, no logra percibir los intereses y necesidades de la comunidad"(CISNEROS, 2006). Esta evaluación 
negativa de las políticas públicas aplicadas en la zona se convirtió en una constante y sumado al cierre de la mina y a la consecuente crisis, generó una representación de abandono por parte de la sociedad y del Estado, que colaboró a la producción de un vacío identitario que permitirá a la mujer asumir nuevos roles en la sociedad. Su "visibilización" como sujeto activo en la economía, la política, la cultura y la sociedad, por tanto se dio gracias a la reconversión productiva en Lota, pero fue una consecuencia no buscada. En ese contexto el rol de la mujer comenzó a cobrar cada vez más relevancia, se insertó en labores en el Centro de Formación Técnica, en el nuevo Banco Estado y principalmente en el comercio minoritario; se integró a organizaciones sociales y alcanzó una notable participación política. Sin embargo, esta situación favorable para la mujer, no fue suficiente para salir de la crisis económica y en el 2007, el 41.9\% de la población lotina, seguía viviendo en condición de pobreza, la indigencia alcanzaba al $9.7 \%$ y la cesantía correspondía al índice más alto del país ${ }^{7}$; Lota seguía siendo una ciudad "cerrada, autorreferida y con escasos vinculos con el exterior” (CARRILLO; LETELIER, 2002. p. 93).

\section{Cuadro $\mathrm{n}^{\circ} 1$ Distribución de Población Comunal por Grupo Etáreos}

\begin{tabular}{|c|c|c|c|}
\hline $\begin{array}{c}\text { Grupo de Edad } \\
\text { y Anhos de Edad }\end{array}$ & Hombres & Mujeres & Ambos Sexos \\
\hline 0 a 14 & 6451 & 6342 & 12.793 \\
\hline 15 a 29 & 5835 & 6128 & 11.963 \\
\hline 30 a 49 & 7053 & 7503 & 14.556 \\
\hline 50 a 79 & 4307 & 4753 & 9.060 \\
\hline 80 y más & 298 & 419 & 717 \\
\hline Total & 23.944 & 25.145 & 49.089 \\
\hline
\end{tabular}

Fuente: $\mathrm{INE}^{8}$

Los índices de participación laboral indican que un 64.1\% corresponde a la población masculina y un 38,3\% a la población femenina. En relación a la tasa de desocupados, un 15\% corresponde a los hombres y un $16.3 \%$ corresponde a las mujeres, lo que muestra un porcentaje levemente mayor de mujeres desempleadas. 
Sin embargo, 3945 mujeres asumía en el 2006 el rol de jefa de hogar. El total de jefes de hogar es de 12.036, de los cuales 8091 son hombres, demostrando que la jefatura de hogar femenina corresponde al 32,8\% $\%$. Si consideramos que en relación al ingreso por jefatura de hogar promedio, el hombre percibe un ingreso de $\$ 239.173$ pesos y la mujer $\$ 167.674$ pesos, comprendemos que los hogares dirigidos por mujeres son bastante más precarios que los dirigidos por hombres $^{10}$. Esto puede verse fomentado por la alta tasa de analfabetismo que alcanza un promedio de $6.4 \%$, y que en las mujeres corresponde a un 7,61\% y en los hombres a un 5.21\%. Se agrega a lo anterior que son los hombres quienes poseen más años de escolaridad; por ejemplo, en el caso de las mujeres mayores de 15 años, la cifra asciende a un promedio de 8.79 años de escolaridad, en contraste con la población masculina que alcanza a 9.41 años de escolaridad ${ }^{11}$.

Todo lo anterior invita a pensar en tres escenarios básicos generados a partir del cierre de la mina, a saber: la crisis estructural que se consolidó en la ciudad, la no incorporación de los hombres en los procesos de reconversión y producción, generando un quiebre al interior de los roles tradicionales que estructuran las dinámicas de poder doméstico y familiar en el seno de sociedades tradicionales en la modernidad y el ascenso de la mujer en ámbitos laborales, que aunque todavía precarios e inestables, permitió la inserción en espacios de los que antes estaba excluida, posibilitando su constitución como sujeto laboral; y como plantea Bauman, en un contexto donde aún prima una ética del trabajo, posibilitó el inicio de su resignificación de su presente y también de su pasado.

La crisis de la sociedad minera provocó por una parte, una reproducción crónica de índices como la pobreza, la cesantía y los salarios variables, pero también un vacío identitario consecuencia del cierre de la mina y la discontinuidad de una labor que por generaciones fue sustento de la cultura de Lota, actividad enunciada y significada como masculina. Claramente, el nuevo rol de la mujer se insertó en un contexto complejo y poco favorable. Con bajos niveles educativos, desde el cierre de las minas ha desarrollado labores discontinuas y variables y ha debido ejercer además como sostenedora del hogar y como nuevo agente económico. Pese a ello, su importancia no sólo radica en este nuevo rol, sino que en la visibilización de un sujeto que ha podido disputar un espacio en 
una sociedad patriarcal y por ende, jerarquizada y heterodesignada desde lo masculino.

\section{La prensa y el conflicto carbonífero: Las representaciones de la mujer}

Las representaciones sociales, tal como indican los estudios fenomenológicos, articulan no sólo tipologías del otro, sino que también las formas en la que los sujetos simbolizan, estructuran y organizan la experiencia respecto de la situación de sí mismos y los otros. En ese plano, la prensa colabora en la construcción social de esas representaciones intersubjetivas. En plena crisis del carbón, es importante la pregunta sobre cómo se representaba a la mujer del carbón y en ese plano, cómo se constituían, en la mitad del conflicto, el conjunto de los imaginarios de género que estaban detrás de las noticias que daban cuenta de la crisis social que atravesaba al carbón.

Es significativo consignar al respecto que la prensa tuvo un manejo diferenciado del conflicto. Así, mientras en el Mercurio el conflicto carbonífero estaba asociado a la crisis de un modelo de intervención estatal, primando el análisis económico neoclásico, en el Siglo se hacía una lectura donde se enfatizaba los conflictos sociales generados por el modelo neoliberal heredado desde la dictadura. En ese sentido, en el diario asociado al Partido Comunista (El Siglo) es más fácil encontrar representaciones de la familia, de la mujer y del hombre minero que en el diario vinculado a la derecha y los poderes fácticos chilenos. La prensa liberal de derecha, como la Tercera, sólo consigna representaciones del obrero y sus familias hacia el año 1996 cuando el cierre definitivo de Schwager y la situación de explosión social en Lota, obligó a cubrir los procesos que quedaban al descubierto de un pueblo que agonizaba con el fin de una actividad económica.

La representación de la mujer durante el conflicto se movió en dos direcciones a lo largo de los años 1992 y 1998. En primer lugar, la representación de la mujer vinculada a lo doméstico y por ende, como parte de la familia minera y víctima del cierre de las minas. En esta forma de construcción lo femenino aparece en la esfera de 
La disputa del pasado: "desmasculinización" del espacio minero...

lo íntimo, al interior del hogar, con los hijos, encargada de "llevar la casa", angustiada por la precariedad del trabajo de su marido y la inestabilidad de un trabajo riesgoso y la incertidumbre del futuro.

La mujer se sentía responsable del funcionamiento de lo cotidiano, de la pequeña e importante parte de ese mundo que se articula en las paredes del hogar minero:

[...] nuestros hombres han entregado su vida en la empresa y hoy se les rechaza y nadie se detiene a pensar que tras un hombre hay una esposa y hay hijos y somos nosotros quienes más sufrimos. Para adelante vemos nuestra labor como dura y negra, continúa Pamela Retamal, porque somos madres y a nosotras nos toca parar la ollita y qué vamos a hacer si no hay trabajo ${ }^{12}$.

En la misma línea representaba a la mujer la revista mensual vinculada a ex militantes del Movimiento de Izquierda Revolucionaria, MIR, cuando recogía la experiencia de mujeres en plena crisis del carbón:

Muchas mujeres se despiden de sus esposos en la mañana, esperando que no sea la última vez que los vean. Pasan el día con un nudo en la garganta que se torna angustia cuando cae la noche y sus maridos aun no regresan a casa. Mientras los mineros trabajan un kilometro bajo el mar, sacando carbón para una empresa en vías de extinción, sus mujeres se las arreglan para poner pan en la mesa y pagar las deudas ${ }^{13}$.

La mujer quedaba relegada al campo de lo doméstico, en la incertidumbre de lo cotidiano y su experiencia de la crisis queda representada con el deterioro de las condiciones de vida al interior del hogar. La mujer era una víctima inocente, al igual que los niños hijos de mineros, una víctima del sistema que generó el cierre de las minas.

En esa representación primó un imaginario de subalternidad de lo femenino, de actor no relevante en lo público y central en lo doméstico y cotidiano. La valorización de la mujer estuvo vinculada al ideario del sostén invisible, del sujeto no reconocido, que 
sale de su espacio privado para reclamar ante las autoridades, no su condición de subalternidad, sino que para proteger su espacio doméstico: "En uno de los hornos comunes varias de ellas se ríen y quejan con facilidad. No han pagado las cuentas y cocinan gracias a que en los negocios de abarrotes les mantienen abiertas las cuentas del fiado" $" 14$.

Sin embargo, muchas de ellas manifestaban a través de la prensa que esta situación de precariedad era casi "consustancial" a la vida minera. Así con un dejo de conformismo ante la situación de adversidad, se narraba a una mujer acostumbrada a las penurias y que miraba con pesimismo la vida pasada y futura. La Tercera recogía el relato de Edia Cabrera, quien recuerda la huelga larga del año 60 que se extendió por más de 96 días y que marca un hito en la memoria del pueblo carbonífero. En dicho relato la mujer expresaba:

[...] a mí me gustaría irme, para darle una buena educación a mis hijos. Mi padre murió en la mina, en un accidente cuando yo tenía 14 años, mi cuñado también. Mi papá me decía que la vida del minero siempre va ser andar de paro para conseguir las cosas. Hija, usted no se case con un minero, y fue lo primero que hice ${ }^{15}$.

Pero junto con esas imágenes que representaban el rol tradicional de la mujer como esposa y madre, se va dibujando otra imagen, que nace al alero de la anterior: La mujer del carbón en el espacio público.

La irrupción de la mujer en el espacio público se graficaba como algo constante a lo largo de la historia del carbón y se encontraba gatillada por la precariedad y la crisis permanente que azota a la industria desde la década del 60. Para la revista Punto Final “[...] las mujeres de los mineros llevan años uniéndose por una causa común. Los frecuentes accidentes mineros, los conflictivos procesos de negociación colectiva con la empresa minera y el hambre, han obligado a las mujeres a organizarse, de manera informal y espontánea"16.

Para la prensa, la defensa del hogar y de las fuentes laborales del hombre-esposo-padre, eran los componentes claves que ayudaban a comprender la irrupción de la mujer en la esfera pública. 
Ellas actuaban para exigir cumplimientos laborales, para apoyar a sus maridos. Su lucha en tanto "mujer" seguía estando asociada a la representación de la madre y la esposa.

Sin embargo, la informalidad de la asociatividad construida cambió su rumbo con la crisis estructural y definitiva del carbón en la década de 1990. La organización esporádica dio paso a nuevas estrategias que posibilitaron la construcción de nuevas experiencias. Así, en 1994 en el marco del cierre de la mina de Schwager, las mujeres crearon una agrupación formal denominada "Comité de Esposas de mineros de Schwager".

El Comité de Esposas de mineros de Schwager reunió a mujeres de mineros despedidos afectados por el cierre definitivo de la mina en Coronel. Su primera aparición pública la registró el diario El Siglo, quien informó de una carta que enviaron ellas mismas al periódico solicitando ayuda material para enfrentar la crisis. Sus solicitudes inmediatas seguían estando vinculadas al rol de madre y esposa, es decir, peticiones que grafican la urgencia de un hogar precario y que requieren resolver en la inmediatez. Las mujeres planteaban que

[...] hemos hecho ya una serie de gestiones tendientes a la obtención de alimentos y entre las organizaciones a las que recurrimos se encuentran ustedes, a quienes estamos solicitando ayuda en alimentos no perecibles, o en su defecto el envío de dinero para hacer frente a las deudas de servicios básicos. La sede que nos cobija como organización de mujeres está ubicada en la calle bulnes 1058, Coronel $^{17}$.

Las mujeres estaban angustiadas porque "[...] muchos de nuestros hogares se encuentran sin los servicios básicos de luz y agua, debido a que han sido cortados por no pago" 18 y eso las habría obligado a organizarse con las otras esposas-madres para dotar de solución inmediata a las urgencias domésticas.

Junto con lo anterior, las mujeres a través de la prensa, esgrimían también que la lucha organizada que están emprendiendo era también una lucha por la dignidad. Es ese paso de significación de su propia actuación la que va permitiendo un pequeño avance hacia dinámicas de politización. María Elena Mansilla declaraba a través del Siglo que 
[...] hemos visto a los hombres llorando, a los mineros del carbón, los palos fuertes, llorar, llorar de impotencia, llorar de amargura porque no tienen pan para sus hijos, no tienen leche para sus pequeños. Es una situación dramática. Eso es como la pérdida de la dignidad y a nosotras nos parece importante, como mujeres, luchar para recuperar nuestra dignidad y generar en nuestros maridos un compromiso mayor. Nosotras estamos con ellos, los vamos a apoyar en todo ${ }^{19}$.

Dibujada así la imagen del hombre rudo, masculino, heroico y fuerte del minero, la mujer visibilizaba la pérdida de la dignidad cuando éste se declaraba impotente, incapaz y ve las puertas del trabajo cerrarse. Ante el deterioro de su rol de proveedor, el hombre llora y las mujeres representan aquello como algo no propiamente masculino, que erosiona las bases constitutivas de una sociedad que tenía el heroísmo minero como componente clave de la identidad social.

Por eso las mujeres organizadas en este comité planteaban con fuerza "queremos fuentes de trabajo para nuestros hombres," junto a esta petición se deslizaba otro requerimiento que complejiza la construcción de la mujer en la esfera pública:

[...] también queremos que se deje de mirar a la mujer del minero como se ha hecho siempre, una mujer que sólo sirve para las labores de la casa. Nosotras queremos que se nos incorpore al mundo del trabajo, que se nos capacite, que nos entreguen herramientas para subsistir con dignidad, señaló Mercedes Fredes finalmente. ${ }^{21}$

A través de este requerimiento, la dignidad también se asociaba a un cambio de situación de la mujer, que ya no solo se visibilizaba como apoyo al marido, al padre o al hijo, sino como ser que quería constituirse en sujeto pleno y así, vinculándose a la ética del trabajo, buscaba en ese espacio la validación de su propia voz.

Estas mujeres de Coronel marcaron la primera irrupción pública de las mujeres en la crisis del carbón. Ellas vinieron a Santiago y se juntaron con Gladys Marín (secretaria general del Partido Comunista en ese entonces), con Luis Maira (ministro del trabajo de 
La disputa del pasado: "desmasculinización" del espacio minero...

la época) y con Josefina Bilbao (ministra del Sernam en 1994); aprovechando de buscar apoyos solidarios con estudiantes, pobladores y trabajadores organizados; visibilizando su demanda político-social a través del uso de la imagen tradicional de la mujer, buscando la inserción de ésta en el mundo laboral y político y dibujando una nueva expectativa para la mujer del carbón.

Cuando la crisis se desató en Lota, a partir del año 1994, las mujeres hicieron apariciones que mantienen los roles tradicionales, pero que combinan con repertorios de lucha más radicalizados. Las mujeres marcharon hacia Santiago en 1996 y cinco de ellas participaron de una huelga de hambre que se extendió por más de 20 días. Ellas mismas reconocían que esta forma de lucha había generado conflictos al interior de los hogares, porque ponía en jaque el orden tradicional de una sociedad patriarcal. El machismo, planteaban, hacía que muchos mineros no permitieran a sus mujeres participar de estas actividades y les prohibíeran salir de sus casas: "Cuando se tomaron el pique, algunos hombres no dejaron a sus esposas siquiera ir a verlos"22. Se comenzaba a delinear claramente el conflicto que se avecinaba ante la cesantía de los proveedores y que permitiría a las mujeres disputar el pasado de la sociedad minera.

\section{Mujer y reconversión productiva}

La división sexual del trabajo, sustrato básico de la sociedad patriarcal, posibilita una construcción del género basada en la transmisión de los tratos diferenciados y la reproducción de los mismos en diversas generaciones, naturalizando el "ser mujer" como madre y recluida en el espacio doméstico. Consecuentemente la educación y el poder económico son pensados para el hombre; por lo mismo, la base de la sociedad, la familia se organiza de manera jerárquica y con estructuras de poder verticales, con criterios de género y edad. La cabeza del hogar es el hombre y la mujer su apoyo. Corsi señala que esta institucionalidad de tipo unidireccional que se funda en torno al hombre, no sustenta el respeto en la reciprocidad, sino en la imposición, estableciendo niveles distintos de jerarquía para hombres y mujeres (CORSI, 2003).

Sin embargo, a partir de fines de la década de 1990, la familia comienza a sufrir transformaciones profundas, consecuencia de la

Anos 90, Porto Alegre, v. 19, n. 36, p. 283-314, dez. 2012 
globalización, los grandes cambios económicos, sociales, culturales y la "modernización" de las relaciones sociales; en otras palabras ha cedido a la imposición del neoliberalismo. Ello conlleva una disminución del rol benefactor del Estado y un aumento de las relaciones de mercado, que conduce a mayores exigencias económicas (VALDÉS, 2004), pero también a la separación entre trabajo remunerado por parte del hombre y el doméstico por parte de la mujer, que "hoy va en retirada" 23 .

Según datos de la Universidad de Chile, a inicios de los 2000, el $50 \%$ de la masa laboral correspondía a mujeres, apoyado por la encuesta CASEN que indica que la participación laboral de la mujer se incrementó alrededor de 15\% entre los años 1978 y 2003 (VALENZUELA et al, 2008). Pese a ello, "mientras se ha ampliado el acceso de la mujer al trabajo remunerado, lo que consume tiempo que tradicionalmente ella dedicaba a cubrir responsabilidades familiares, no se ha producido un cambio equivalente en la redistribución del tiempo que los hombres dedican al trabajo y al hogar" (SUNKEL, 2006).

En ese contexto, el cierre de la mina de Lota en 1997 se genera en un marco de mayor incorporación global de la mujer al espacio laboral. Sin embargo, el trabajo femenino "[...] al estar acompañado de una aculturación heterodesignada, se sitúa en una ciudadanía laboral de segunda categoría, trayendo consigo las consecuencias de emplear a las mujeres en lugares precarios y desvalorizados socialmente. Perciben menores ingresos porque se ubican en empleos precarios, con jornadas laborales flexibles de tiempo parcial y medias jornadas, para poder conciliar el trabajo familiar-doméstico con el trabajo asalariado"(NUÑEZ, 2010), justo en el mismo momento en que los hombres, sostén tradicional del hogar minero, quedaba excluido de las promesas del desarrollo y no lograba situarse en el nuevo escenario generado por una reconversión fracasada.

Así mientras los hombres se refugiaban en las esquinas con sus antiguos pares de labores en las minas, las mujeres intentaban aprovechar los nuevos espacios laborales, que aunque precarios y flexibles, les permitían palear en algo las numerosas necesidades del hogar minero, ahora sin mineros a su cabeza. Parte importante del proceso de instalación de la mujer en el espacio público estuvo asociado al rol que jugaron numerosas ong's, que al alero de 
La disputa del pasado: "desmasculinización" del espacio minero...

programas financiados por el Sernam y el Fosis, posibilitaron la entrega de nuevas herramientas laborales, pero también de resignificación del rol de la mujer en los espacios tradicionales.

En conjunto con la anterior, la experiencia de participación política de las mujeres lotinas y de Coronel en las movilizaciones de los años 96 y 97, permitieron la consolidación de lazos sociales más amplios que la mera relación doméstica de dueñas de casa. Ellas acompañaron a los mineros y pese a que fueron representadas como actores tradicionales, su propia resignificación de la experiencia de lucha las ha llevado a tomar protagonismo más allá del cierre de la actividad minera, tal como lo hicieron con la toma de la mina abandonada en el año $2010^{24}$. Por ello constatamos que su participación política ha ido en ascenso, cuestión que se ejemplifica con la cifra de inscritos en el registro electoral (2007) en el que las mujeres superan ampliamente a los hombres ${ }^{25}$ y aunque dicha comuna nunca ha tenido una alcaldesa, actualmente el 50\% de sus concejales son mujeres. De los 12 cargos directivos en planta, 5 son ocupados por mujeres. En tanto, al interior del municipio de Lota, la distribución total de la planta municipal tiene un $58.7 \%$, correspondiente a varones, y un $41,4 \%$ correspondiente a mujeres ${ }^{26}$. Pese a ello, las mujeres perciben que su participación social es segregada a espacios que mantienen el rol tradicional de ellas, como los Centro de Madres, los Talleres laborales o los Consejos de Salud, mostrando una actitud crítica respecto de su presente y el espacio que ocupan en él.

Intentando modificar esta situación, han constituido organizaciones que fomentan la superación económica y la ayuda social, como el "Grupo de mujeres y el Grupo de Adulto mayor Esperanza", el Club de Adultos Mayores "Blanca Ema", el "Grupo Mujeres Las Violetas" y "Génesis" y el Taller de Mujer "Baldomero Lillo"; todas con apoyo del "Programa de la Mujer" a cargo de la Municipalidad, fomentando el desarrollo de manualidades, emprendimientos microempresarios y círculos de debate y discusión ${ }^{27}$.

Otro notable ejemplo es el surgimiento de la "Casa de la Mujer", fundada en 1997, coincidiendo con el cierre de la mina, "como iniciativa y producto de un grupo de mujeres líderes que desarrollaban acciones sociales en la comuna y que organizadas deciden enfrentar la situación de quiebre económico [...] Seis años más tarde, posicionadas y fortalecidas institucionalmente se transforma 
en una Organización no Gubernamental, mediante la figura de Corporación" ${ }^{28}$; desarrollando vínculos de cooperación más estables, promocionando la participación social y fomentando la capacitación y la educación mediante becas y créditos blandos a mujeres emprendedoras.

Todo lo anterior, invita a pensar que la mujer, a partir de fines de la década de 1990 no sólo se incorporó a espacios de participación política y cultural, sino que cumplió un rol trascendental en la reconversión productiva de la ciudad. Se empleó en el Centro de Formación Técnica, en el Banco Estado y en el comercio minoritario y ejerció un importante papel en la economía, manteniendo pese a todo, su rol de madre, esposa - en muchos casos - y articuladora del hogar. A escala comunal en el 2002, en Lota el 22.3\% de las mujeres eran jefas de hogar, superando el promedio de la región y pese a ello, el 17.3\% poseía trabajos informales, por lo tanto ingresos discontinuos y variables. El 15.9\% se declaraba jubilada o pensionada lo que nos hace suponer que es probable que se trate de mujeres viudas con hijos o que reciban pensiones de gracia o la ayuda de algún familiar para subsistir. Sólo el 2.2\% estudiaba, ello se condice con una carencia de formación y de preparación para el mundo laboral, ya que el $61.2 \%$ de la población jefa de hogar estudió hasta el nivel básico; el 25.1\% estudió hasta la educación media incluyendo la educación técnica y sólo el 1.1\% tiene estudios superiores ya sea técnicos o universitarios; el 12.5\% no posee instrucción ${ }^{29}$.

Ello probablemente responde a que en familias de escasos recursos, como las de Lota "Cuando disminuye el ingreso familiar - específicamente, cuando el jefe de hogar pierde el empleo - la respuesta más común es que las mujeres ingresen al mercado laboral. Esta respuesta de la mujer - que es una forma de solidaridad familiar para compensar o sustituir la pérdida de ingresos del hombre jefe de hogar - se da en todos los estratos socio-económicos, pero muy especialmente en los más pobres"(SUNKEL, 2006. p. 7). Ello idealmente, conduce a mayores niveles de bienestar o por lo menos, salir de la pobreza, es "una estrategia de afrontamiento orientada a adecuarse a los impactos negativos" (SUNKEL, 2006. p. 7) de la falta de ingresos. Por ello, la mujer asume crecientes grados de autonomía, primero económica y luego cultural y política, mediante su participación y la activación de sus demandas de género y de clase. 


\section{La disputa por el recuerdo: Femenizando y desmasculinizando el pasado minero, entre la añoranza y el presente}

La posición que se ocupa en un presente en construcción, implica también procesos de resignificación del pasado, sobre todo porque ello permite construir identidades colectivas e individuales. De allí que constantemente se vislumbren memorias en pugna, que ante la invisibilización social pretenden situarse y narrarse dentro de un pasado masculinizado en un sistema patriarcal y heterodesignado. Este es el caso de las mujeres de Lota, quienes dentro de sus tradicionales roles, han asumido grados crecientes de incorporación y participación, no sólo en la economía, sino que también en la sociedad y en la política de Lota. Dentro de esa lógica, las mujeres han elevado un discurso asociado al no reconocimiento de su importancia en el pasado y la necesidad de "hacerse respetar" en el presente y para el futuro.

Los cambios, aunque no hegemónicos, al interior del hogar, resitúan a la mujer y la llevan a reflexionar sobre su pasado vivido. Es en ese proceso se va buscando posicionar a la mujer en el pasado minero, donde se reconocía como actor central al hombre y que le daba a ésta sólo un lugar de compañía subalterno. Hoy cuando las mujeres son los principales agentes activos en la mantención y recuperación del pasado lotino en perspectiva patrimonial, han instalado allí una disputa por desmasculinizar parte de esa narrativa, para resituarse en ella.

A partir de la reconversión, las mujeres han pasado a ser "la esperanza de lota" y los hombres, en su monofuncionalidad se han convertido en el germen del problema, al no haberse readapatado a la economía lotina, ello porque "La designación de tal transformación - reconversión - aparece como un elemento que parece expresar tanto una percepción de imposibilidad de continuidad de una identidad tradicional (en tanto mineros), cuanto la imposibilidad de asumir una identidad nueva [...] En el vacío de la identidad sólo quedaba la sobrevivencia" (PALMA; VILLELA, 1997). Sin embargo, al ser las mujeres las que han recuperado parte de la vida cultural lotina, le han impreso importantes procesos de resignificación a ese pasado, que si bien fósil como actividad económica, está abierto a la disputa por su narración. 
Así lo afirman cuando entrevistados plantean que: "Hoy día estamos buscando nuestra identidad, no sabemos si somos mineros, portuarios, comerciales, forestales, turísticos o qué, pero en general seguimos viviendo una búsqueda desde el cierre de la mina". En esa búsqueda de identidad se cuestiona al hombre heroico y se le califica de inflexible, porque ellos "[...] no saben trabajar en otra cosa que no sea la mina y debido a la especialización del trabajo no se acostumbran a los nuevos oficios" ${ }^{30}$. Así lo que antes era fuente de orgullo constituye hoy un problema y eso obliga a remirar el pasado, cuestionarlo y ponerlo en tensión. En ese pasado, las más flexibles, las que mejor se adaptaban a las condiciones adversas son las mujeres, porque vivían fuera de las minas, pero también porque eran ellas las que se sitúan como las claves en la mantención de un hogar precario e inestable.

Las mujeres plantean que "El hombre sigue añorando la mina, en cambio la mujer ya cambió su actitud" ${ }^{31}$, por ende, entienden que esa añoranza se ha vuelto más un inconveniente que algo positivo. Según algunas entrevistadas, los hombres "pasan todo el día metidos en la casa y sólo algunos se han reinsertado en otras labores, la mayoría se ha convertido en taxista o pescador y muchos se han ido de la ciudad"32. El minero, en suma, no sabe hacer otra cosa que estar en la mina y cuando esta se cerró, quedó de brazos cruzados; en cambio, las mujeres no han estado en la mina, pueden reinsertarse, su mundo exterior siempre fue más variado, allí ellas se construyeron, lo que las ha llevado a relevar la importancia de las dinámicas de sociabilidad que construyeron en los hornos colectivos, en los centros de madres, en los clubes sociales.

Los cambios en las dinámicas domésticas, resitúan a la mujer y al hombre y dibujan al mismo tiempo una tensión dentro de la sociedad patriarcal

Yo era dueña de casa, pero luego de la reconversión me puse a trabajar como auxiliar en un colegio, porque nos faltó plata en la casa. Mi marido es sindicalista actualmente y pescador, pero eso significan sueldos variables, por eso yo soy la que sostengo el hogar y él quien hace el aseo"33, "Con la crisis generada por la reconversión, las parejas entraron en crisis y muchas se separaron, porque sin trabajo,

Anos 90, Porto Alegre, v. 19, n. 36, p. 283-314, dez. 2012 
La disputa del pasado: "desmasculinización" del espacio minero...

los hogares se desorganizaron, algunos salieron a buscar trabajo para afuera y no volvieron nunca más, entonces las mujeres tuvieron que entrar a tomar el rol del hombre no más y se pusieron a trabajar ellas ${ }^{34}$.

Complementariamente, se agrega que

Como la mujer estuvo mucho tiempo invisibilizada tenía miedo de hablar o de opinar, ella estaba acostumbrada a andar detrás del marido, nunca a su lado. Cuando se acabó la dictadura y poco a poco comenzó a cambiar el tema de la participación política y sobre todo después de la reconversión, la mujer empezó a darse cuenta de que necesitaba hablar y opinar, porque ya el hombre no era el único que tenía que tener el sustento para la familia. La mujer después de eso salía a trabajar y empezaron a inculcarle a los hijos que el trabajo era para todos igual [...] las mujeres nos dimos cuenta de que también podemos participar y ganar nuestro propio dinero y no depender de nadie ${ }^{35}$.

En suma, a la añoranza del pasado minero por parte de los hombres, se presenta una paradoja fundamental en la sociedad carbonífera, pues por una parte se sigue reproduciendo una sociedad patriarcal, arraigada a un pasado masculinizado, pero por otra se integran nuevas dinámicas sociales protagonizadas por mujeres que han feminizado el presente y desde allí han tomado las riendas de disputar las narrativas del pasado, buscando los espacios que ese mundo pretérito les tenía invisibles a través de participar de los espacios público y del rescate patrimonial de las ciudades mineras del carbón.

\section{THE DISPUTE OF THE PAST: DESMASCULINIZATION THE MINING SPACE. THE EFFECTS OF LABOR AND PRODUCTIVE RECONVERSION IN LOTA AND CORONEL.}

Abstract: The terminal crisis of the coal-bearing industry in Chile generated a social significant crisis in Arauco's basin. The policies of labor and productive restructuring implemented by the first two governments of the Conciliation were a failure. Nevertheless, the above mentioned policies had a not looked 
effect. While the ex-miners were turning into chronic suspended civil servants, the women took advantage of few labor available offers and went out of the domestic world to turn into bosses of home. In this work we will approach how it impressed this process of women's incorporation to the labor world, in the dispute for the resignificance of the past of the mining society.

Keywords: World of coal, Memory, Cultural transformations.

\section{Notas}

${ }^{1}$ Articulo elaborado en el marco del proyecto de inserción posdoctoral $\mathrm{n}^{\circ}$ 79090004.

${ }^{2}$ Citado por Vivallos y Brito. Op. Cit. p. 36-37

${ }^{3}$ Fundación Instituto de Estudios Laborales, "Estudio Cuantitativo y Cualitativo sobre la Realidad Laboral en las Comunas de la Cuenca del Carbón", 2009

${ }^{4}$ Cuadro extraído de Cisneros, Nicolás. Evaluación de las Políticas Públicas Aplicadas tras el Cierre de la Industria Carbonifera en Lota, Región del Bio-Bio. Una Mirada desde el Capital Social y la Participación ciudadana. Tesis para Optar al Título de Sociólogo. Universidad de Concepción, 2006

${ }^{5}$ Reporte estadístico comunal: Lota, Instituto Nacional de Estadísticas, abril 2008

${ }^{6}$ Diario El Sur, 16 de Abril de 2007.

${ }^{7}$ Datos extraídos de <http://www.sepade.cl/media/files/publicaciones/lota.pdf>

${ }^{8}$ Para el año 2002. Diagnóstico Comuna de Lota, Informe Preliminar, proyecto “Todas las manos todas". Programa Desarrollo y Participación ciudadana. SEPADE

${ }^{9}$ Fuente: CASEN 2006. < www.mideplan.cl>

${ }^{10}$ Fuente: CASEN 2006. <www.mideplan.cl>

${ }^{11}$ Fuente: PADEM 2008. Municipalidad de Lota

${ }^{12}$ Diario El Siglo, 17 de noviembre de 1994.

${ }^{13}$ Revista Punto Final, julio de 1996.

${ }^{14}$ Diario La Tercera, 16 de junio de 1996.

${ }^{15}$ Diario La Tercera, 16 de junio de 1996.

${ }^{16}$ Revista Punto final julio de 1996.

${ }^{17}$ Diario El Siglo 5 de noviembre de 1994.

${ }^{18}$ Diario El Siglo 5 de noviembre de 1994.

${ }^{19}$ Diario El Siglo 5 de noviembre de 1994.

${ }^{20}$ Diario El Siglo 5 de noviembre de 1994.

${ }^{21}$ Diario El Siglo 5 de noviembre de 1994.

${ }^{22}$ Revista Punto Final, julio de 1996.

${ }^{23}$ Datos extraídos de <http://www.eclac.cl/publicaciones/xml/9/31999/LP96_ Familia_lcg2345.pdf $>$ 
La disputa del pasado: "desmasculinización" del espacio minero...

${ }^{24}$ Datos extraídos de < http://www.cooperativa.cl/las-33-mujeres-del-chiflon-del-diabloen-lota-iniciaron-huelga-de-hambre/prontus_nots/2010-11-17/091126.html>. Se complementan en <http://www.americaeconomia.com/politica-sociedad/mundo/ chile-33-mujeres-se-encierran-en-una-mina-para-exigir-la-extension-de-progra $>$ ${ }^{25}$ SERVEL, Inscritos al 30 de diciembre de 2008, en: <www.servel.cl> ${ }^{26}$ Fuente: SINIM 2007. <www.sinim.cl>

${ }^{27}$ Datos extraídos de < http://www.sepade.cl/media/files/publicaciones/lota.pdf $>$

${ }^{28}$ Memoria Institucional: Casa de la Mujer, Creando nuevas miradas, 1997-2006.

${ }^{29}$ Datos extraídos de http://www.sepade.cl/media/files/publicaciones/lota.pdf

${ }^{30}$ Hombre, Don Juan, Sindicalista y ex minero, 60 años, 2009.

${ }^{31}$ Mujer, Sra. Rosa, esposa de ex-minero, auxiliar en un colegio, 52 años, 2009

32 Ibídem

${ }^{33}$ Ibídem

${ }^{34}$ Hombre, Raúl, Ex minero, 58 años, 2009.

${ }^{35}$ Mujer, Sra. Susan, esposa de ex-minero, Miembro de La Casa de la Mujer, 54 años, 2009

\section{Referências:}

ALVAREZ, Elizabeth Ortiz y SOTO, María Eliana Vega. Identidad y cultura minera. Fondo de Desarrollo de la Cultura y las Artes, MINEDUC. 1994

ARFUCH, Leonor. Pensar este tiempo. Espacios, afectos y pertenencias. Paidós, Buenos Aires. 2005.

ARÓSTEGUI, Julio. La historia vivida. Sobre la historia del presente. Alianza Editorial, Madrid. 2004

ATORQUIZA, Octavio. Lota. Antecedentes históricos, con una monografía de la Compañia Minera e Industrial de Chile. Sociedad Imprenta y Litografía "Concepción", Concepción. 1929

BAEZA, Manuel Antonio. Imaginarios sociales. Apuntes para la discusión teórica y metodológica. Editorial Universidad de Concepción. 2003

- Los caminos invisibles de la realidad social. Ensayo de sociología profunda sobre los imaginarios sociales". Ediciones RIL, Santiago. 2000

BERTAUX, Daniel. Los relatos de vida. Perspectiva etnosociológica. Ediciones Bellaterra, España. 2005

CARRILLO, Olga y Letelier Andrea. "Memorias colectivas para un balance de la reconversión en Lota 1992-2002”. Tesis para optar al grado de Licenciada en Historia y Ciencias Sociales. Universidad de Concepción. 2002 
CISNEROS, Nicolás. Evaluación de las Políticas Públicas Aplicadas tras el Cierre de la Industria Carbonifera en Lota, Región del Bio-Bio. Una Mirada desde el Capital Social y la Participación ciudadana. Tesis para Optar al Título de Sociólogo. Universidad de Concepción, 2006

CORSI, Jorge. Maltrato y abuso en el ámbito doméstico, Paidos, Buenos Aires, Argentina. 2003

DE BARBIERI, Teresita: "Sobre la categoría género. Una introducción teóricometodológica". Revista Interamericana de Sociología. Año VI, n. 2-3. 1992.

DIAGNÓSTICO Comuna de Lota. Informe Preliminar, proyecto "Todas las manos todas". Programa Desarrollo y Participación ciudadana. SEPADE

FIGUEROA, Consuelo. Revelación del subsolé. Las mijeres en la sociedad minera del carbón 1900-1930. ICSO. Santiago, Chile. 2009

FUNDACIÓN Instituto de Estudios Laborales. "Estudio Cuantitativo y Cualitativo sobre la Realidad Laboral en las Comunas de la Cuenca del Carbón”, 2009.

JERÉZ, Andrea. "Intervenciones urbanas en Lota Alto (1997-2004): Nuevos espacios y equipamientos públicos en la conformación de su identidad”. Tesis para optar al grado de Licenciada en Historia y Ciencias Sociales. Universidad de Concepción. 2004

LAMAS, Marta. "La antropología feminista y la categoría género". Nueva antropología, n. 30, 1986.

MARTÍNEZ, Luis Ortega. "La industria del carbón en Chile entre 1840-1880". Cuadernos de Humanidades n.1. Santiago. 1988

MEMORIA INSTITUCIONAL: Casa de la Mujer, Creando nuevas miradas, 1997-2006

MONTECINO, Sonia. “De la mujer al género: implicancias académicas y teóricas”; en CIEG, Módulo Teorías de Género, FACSO, Universidad de Chile. 1996 MORALES, Marcela. "Mujer y género en las narrativas de la militancia de izquierda de fines del siglo XX: Chile y Argentina en las post dictaduras". Examen de calificación Doctorado en Estudios Americanos, IDEA-USACH. Santiago, Chile. 2011.

MOYANO, Cristina. "Patrimonio, memoria e identidad. Espacio carbonífero, crisis y resignificación: el caso de Lota, Chile (1990-2009)", en Bresciano, Juan A. La memoria histórica y sus configuraciones temáticas. Una aproximación interdisciplinaria. Ediciones Cruz del Sur, Montevideo, Uruguay. 2011.

"Las representaciones de la crisis del carbón: izquierda y derecha en la disputa por la construcción de la realidad social. Lota, Chile. 1992-1998” Ponencia presentada en el Congreso FIEALC, Valencia, julio 2011. 2011b.

Anos 90, Porto Alegre, v. 19, n. 36, p. 283-314, dez. 2012 
NUÑEZ, Isabel. "Yo he trabajado toda la vida: Representaciones sociales del trabajo femenino en Chile, 1970-1992”. Tesis para optar al grado de Magíster en Estudios de Género y Cultura Mención Humanidades, Universidad de Chile. 2010.

ORTEGA, Luis. "El mundo del carbón en el siglo XIX", en "Mundo minero. Chile, siglos XIX y XX”. Universidad de Santiago de Chile. 1992

ORTIZ, Enrique Figueroa; AMBIADO, Carlos Sandoval. "Carbón: Cien años de Historia (1848-1960)". CEDAL. Santiago. 1987

PALMA, Samuel y VILLELA, Hugo. Salir del mundo... salir de la mina: Identidad minera e identidad evangélica de la zona del carbón. CEPADE. 1997

PLATH, Oreste. Folclor del carbón en la zona de Lota. Fondo de cultura económica. Edición corregida y anotada por Karen Müller. $3^{\circ}$ edición. 2008

Reporte estadístico comunal: Lota, Instituto Nacional de Estadísticas, abril 2008.

SARLO, Beatriz. Tiempo pasado. Cultura de la memoria y giro subjetivo. Una discusión. Ed. Siglo XXI, Buenos Aires, Argentina. 2005

SCOTT, Joan. "El género: una categoría útil para el análisis histórico”, En: Armelang y Nash, Edits. Historia y Género: Las mujeres en la Europa moderna y contemporánea. Edic. Altons El Majnanim, 1990. (1985)

SUNKEL, Guillermo. "El papel de la familia en la protección social en América" en Serie Politicas Sociales No.120, CEPAL, Santiago, Chile. 2006

VALDÉZ, Ximena; VALDÉS, Teresa. Familia y vida privada ¿Transformaciones, tensiones, resistencias o nuevos sentidos? Editorial Clacso Chile, 2005. Y del documento: Cambio de las familias en el marco de las transformaciones globales: necesidad de políticas públicas eficaces. CEPAL, Santiago. 2004.

VALENZUELA, Julio; TIRONI, Eugenio; SCULLY Timothy. El eslabón perdido, familia, modernización y bienestar en Chile. Editorial Taurus, Santiago. 2008

VIVALLOS, Carlos y BRITO, Olga. "Trabajo y exclusión en el proceso de modernización de Chile contemporáneo. El caso de los mineros del carbón de Lota”. En Observatorio Latinoamericano n. 8. Facultad de Ciencias Sociales, Universidad de Buenos Aires. Instituto de Estudios de América Latina y El Caribe, Buenos Aires. 2011.

Recebido em 13/12/2011

Aprovado em: 18/05/2012 